\title{
Quorum quenching, biological characteristics, and microbial community dynamics as key factors for combating fouling of membrane bioreactors
}

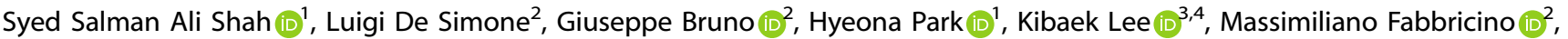 \\ Irini Angelidaki iD ${ }^{5}$ and Kwang-Ho Choo $\mathbb{D}^{1,3 \times}$
}

Membrane fouling is a major challenge in membrane bioreactors (MBRs) for wastewater treatment. This study investigates the effects of disturbance and solid retention time (SRT) on quorum-quenching (QQ) MBRs relative to antifouling efficacy and microbial community change. The fouling rate increases with the applied disturbance at a short SRT, counteracting the antifouling effect of $\mathrm{QQ}$; however, it decreases with QQ at a long SRT. The microbial community appears to be responsible for such MBR behaviors. Several bacterial species belonging to the biofilm-forming group are dominant after disturbance, resulting in substantive membrane fouling. However, the balance between the bacterial species plays a key role in MBR fouling propensity when stabilized. Koflera flava becomes dominant with $\mathrm{QQ}$, leading to reduced membrane fouling. QQ makes the MBR microbial community more diverse, while lowering its richness. QQ with long SRT would be a favorable operational strategy for effective MBR fouling control.

npj Clean Water (2021)4:19; https://doi.org/10.1038/s41545-021-00110-9

\section{INTRODUCTION}

Membrane fouling is the major technical challenge limiting the broader adoption of membrane bioreactors (MBRs) in wastewater treatment and reclamation ${ }^{1-3}$. The key factors involved in membrane fouling include wastewater composition, membrane and membrane module characteristics, and operating conditions. The interaction between mixed liquor constituents and membranes in an MBR appears to be the factor most responsible for membrane fouling ${ }^{4}$. Solid retention time (SRT) is an important parameter influencing mixed liquor constituents (including activated sludge) in $\mathrm{MBRs}^{5}$. Researchers have found that SRT affected MBR fouling propensity, because biomass content increases with increasing SRT, simultaneously reducing the foodto-microorganism ratio ${ }^{6}$. The SRT had additional influences on MBR biopolymer characteristics, such as the excretion of extracellular polymeric substances (EPSs) and soluble microbial products (SMPs), both of which are considered major membrane foulants ${ }^{7}$. Previous research reported that EPS and SMP concentrations decreased with increased SRT, thus alleviating fouling ${ }^{8,9}$. However, a contradictory report showed greater degrees of membrane fouling at high SRTs ${ }^{10}$. Therefore, further studies on SRT's effects on MBR membrane-fouling propensities are needed.

SRT changes the microbial ecology of activated sludge in an MBR, thus influencing biofouling behaviors ${ }^{11-13}$. Biofouling occurs when biofilms form on membrane surfaces and is known to be closely linked to microbial cell-to-cell communication through small diffusible signal molecules, known as quorum sensing $(\mathrm{QS})^{14}$. There are several approaches to inhibit the bacterial QS system, a process known as quorum quenching (QQ), to interfere with biofilm formation ${ }^{15,16}$. The first QQ approach used a QQ enzyme (porcine kidney acylase I) ${ }^{17}$. This strategy targeted the signal molecule $\mathrm{N}$-acylhomoserine lactones, successfully demonstrating
MBR-biofouling retardation. Microbial QQ strategies for MBRbiofouling control using indigenous $\mathrm{QQ}$ bacteria rather than $\mathrm{QQ}$ enzymes have also been developed. The isolate Rhodococcus sp. $\mathrm{BH} 4$ was the first QQ bacterium used for MBR-biofouling control ${ }^{18}$. Since then, several indigenous QQ bacteria, such as Bacillus sp. $\mathrm{T}^{19}{ }^{19}$, Delftia sp. T6 ${ }^{19}$, Bordetella hinzii S3 ${ }^{20}$, Enterococcus sp. HEMM$1^{21}$, Acinetobacter bereziniae strain (ATCC 17924) homolog 22 , and Acinetobacter sp. DKY $-1^{23}$, have been isolated and tested for their QQ activities and membrane-biofouling control capabilities ${ }^{16,24}$. Recently, novel indigenous facultative QQ strains (Pseudomonas sp. KS2 and KS10), which have ambidextrous biofouling control activities for both aerobic and anaerobic MBRs, were isolated and characterized $^{25}$.

It has also been reported that $\mathrm{QS}$ and $\mathrm{QQ}$ bacteria coexist in activated sludge in MBRs, meaning that the antagonism between these types of bacteria could influence sludge properties, bioflocculation, and fouling ${ }^{16,26}$. Another study showed that SRT altered the abundance of bacterial groups due to $\mathrm{QS}$ and $\mathrm{QQ}$ activities in the MBR microbial community, which influenced the biofilm formation responsible for membrane biofouling ${ }^{27}$. However, SRT's effects on QQ media-assisted antifouling efficacies and MBR microbial community structures are not yet well elucidated.

In addition, factors exposing stress to the microbiomes, such as shear forces, starvation conditions, dissolved oxygen (DO) content, and the presence of antibiotics, also affect MBR membrane fouling by altering mixed liquor characteristics ${ }^{28-30}$. The recommended velocity gradient range for biological treatment systems is $40-80 s^{-131}$, but higher levels of shear can be applied to MBRs, to minimize membrane fouling. Aeration intensity affected the hydrodynamics and DO levels of mixed liquor in the MBR, but the effects diminished at high biomass levels $(>10 \mathrm{~g} / \mathrm{L})$ due to increased sludge viscosity ${ }^{32}$. Starvation or low food-to-microorganism ratio

\footnotetext{
${ }^{1}$ Department of Environmental Engineering, Kyungpook National University, Daegu, Republic of Korea. ${ }^{2}$ Department of Civil, Architectural, and Environmental Engineering, University of Naples Federico II, Naples, Italy. ${ }^{3}$ Advanced Institute of Water Industry, Kyungpook National University, Daegu, Republic of Korea. ${ }^{4}$ Department of Biotechnology and Bioengineering, Chonnam National University, Gwangju, Republic of Korea. ${ }^{5}$ Department of Chemical Engineering, Technical University of Denmark, Lyngby, Denmark. email: chookh@knu.ac.kr
} 

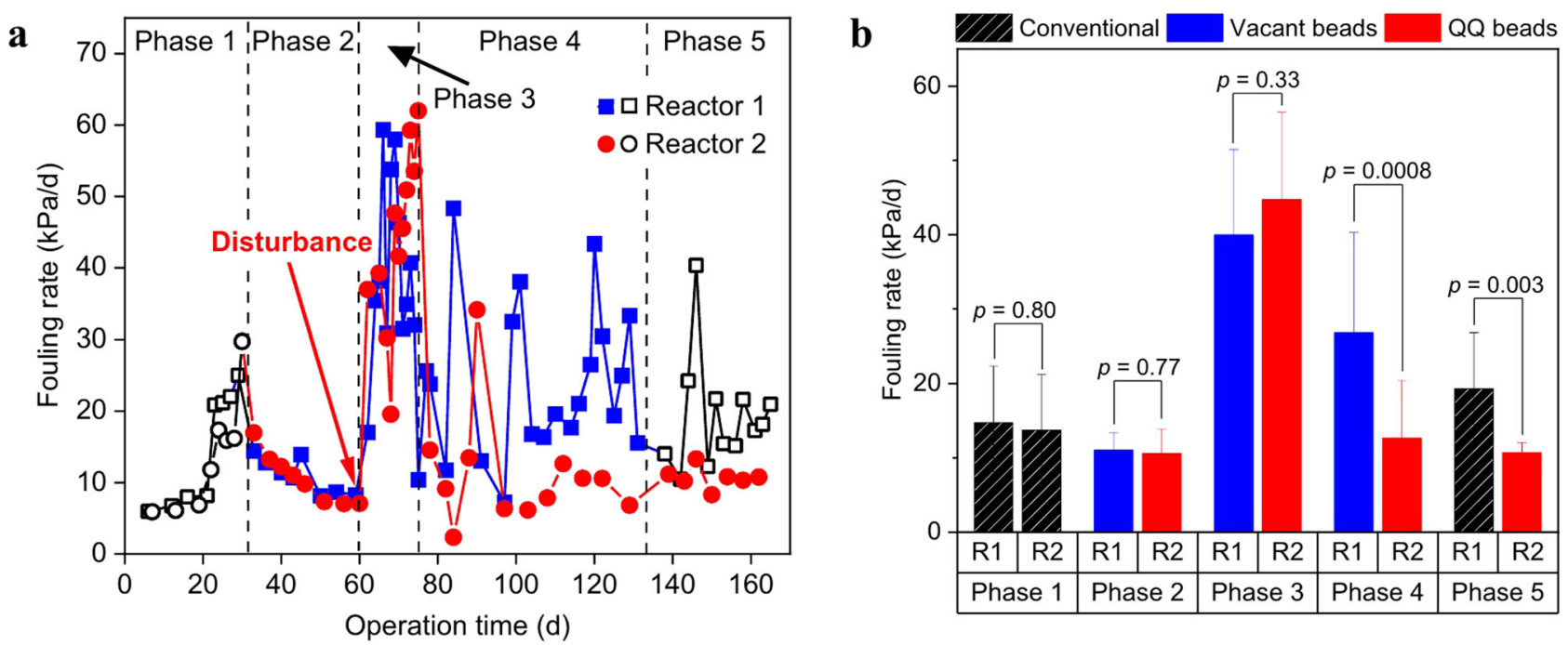

Fig. 1 Membrane-fouling rate. a Its variations with time for Reactor 1 (R1) and Reactor 2 (R2). Each data point indicates the average fouling rate for each MBR run. b Average fouling rates with $t$-test probability $(p)$ values for each phase. Error bars indicate 1 SD. Details on the experimental conditions are provided in Table 2.

increased mixed liquor biopolymer content, leading to increased membrane fouling ${ }^{33}$. Low DO levels $(<0.1 \mathrm{mg} / \mathrm{L})$ led to a greater fouling tendency (7.5 times) than high DO concentrations (>3.0 mg/L) because of denser membrane-biofouling layer formation at low DO levels ${ }^{34}$. The effects of environmental stress on QQ MBR are thus of great interest, because real MBR facilities often encounter such situations.

Therefore, in this study we investigated the impact of SRT and operational disturbance on antifouling efficacy and microbial community structure in MBRs with and without QQ. A stressful environment (starvation with high shear) was implemented in the middle of MBR operation while monitoring membrane fouling pattern and microbial community structure changes. We also evaluated key MBR characteristics, such as biopolymer production, mixed liquor properties, and treatment efficiencies, and their correlations with MBR fouling rates.

\section{RESULTS AND DISCUSSION}

\section{Effects of imposed disturbance and SRT on QQ-based antifouling efficacy}

Figure 1 shows the fouling rate profiles of MBRs over time under different operating conditions, summarizing the average fouling rates of each phase. Two representative transmembrane pressure (TMP) profiles, the average fouling time, and the number of MBR runs at each phase are also provided in Supplementary Fig. 1 and Supplementary Table 1. In Phase 1, the average fouling rates for Reactors 1 and 2 were nearly the same, i.e., there was no statistically significant difference between the reactors. This confirms that the MBRs were in identical states, in terms of fouling behavior when operated in the conventional mode. In Phase 2, the average fouling rates of Reactors 1 and 2 were also almost the same, showing that the $\mathrm{QQ}$ effect on fouling mitigation appears to be insignificant. Unlike previous reports on the $\mathrm{QQ}$ effect on antifouling efficacy ${ }^{35}$, it was unclear whether QQ played a role in fouling control under Phase 2 conditions. One possible reason for the difference is SRT, which will be further investigated and discussed later. After disturbance ( $2 \mathrm{~d}$ starvation with a high shear rate of $103 \mathrm{~s}^{-1}$ ) was applied to both MBRs at the beginning of Phase 3, both MBRs experienced severe fouling phenomena, with sharp increases in the average fouling rate at $>40 \mathrm{kPa} / \mathrm{d}$. No QQ effect was observed in this phase either. The applied disturbance may have caused a drastic change in mixed liquor characteristics, probably including the microbial community structure, while aggravating fouling propensities, which will be discussed further in later sections.

To examine how SRT affects membrane fouling in the MBRs, we increased SRT from 50 to $75 \mathrm{~d}$ in Phase 4 . The average fouling rate of Reactor 1 slightly decreased with vacant beads (which contain no QQ bacteria), whereas that of Reactor 2 decreased more significantly with QQ beads (corresponding to $47 \%$ of that of Reactor 1). With the longer SRT, it appears that QQ affected biofouling mitigation. When Reactor 1 was switched to conventional mode in Phase 5 , its membrane fouling rate was slightly reduced compared to Phase 4 . This implies that the vacant beads had no effect on fouling mitigation and in fact may have caused membrane fouling. A previous study also reported that membrane fouling increased when the media added were trapped inside the membrane fibers ${ }^{36}$. However, Reactor 2 exhibited a notably slower fouling rate, which corresponds to $55 \%$ of that of Reactor 1 . Thus, the biofouling control due to QQ was evident at long SRT (75 d). The effect of SRT on QQ will be discussed further in later sections, along with the time-series data of MBR operational performance and microbial community.

Effects of QQ, disturbance, and SRT on biopolymer production Figure $2 a-d$ show EPS and SMP variations during MBR operations with and without QQ at different SRT values. The EPS and SMP data normalized to mixed liquor suspended solids (MLSS) are also provided in Supplementary Fig. 2. During Phase 1, when the MBRs were operated in the conventional mode, the EPS-carbohydrate (EPS-C) and EPS-protein (EPS-P) levels were similar in both MBRs ( 20 and $80 \mathrm{mg} / \mathrm{L}$, respectively). Notably, however, there was only $\sim 3 \%$ probability that the EPS-P level between Reactors 1 and 2 occurs by chance. One possible explanation is that the microbial communities in both the reactors should change as a result of the provision of synthetic wastewater, leading to alterations in metabolic products. A previous study also reported that fluctuations in EPS-P level at the beginning of MBR operation were observed due to bacterial acclimation to new environments ${ }^{13}$. In Phase 2, the EPS-C concentration decreased by $~ 13.5 \%$ in Reactor 1 compared with that of Phase 1, but decreased by $33.1 \%$ in Reactor 2. However, the EPS-P concentrations in both reactors remained virtually unchanged. It seemed that the lower EPS levels with $\mathrm{QQ}$ did not virtually contribute to fouling mitigation, possibly because its levels were still too high to make a perceptible 

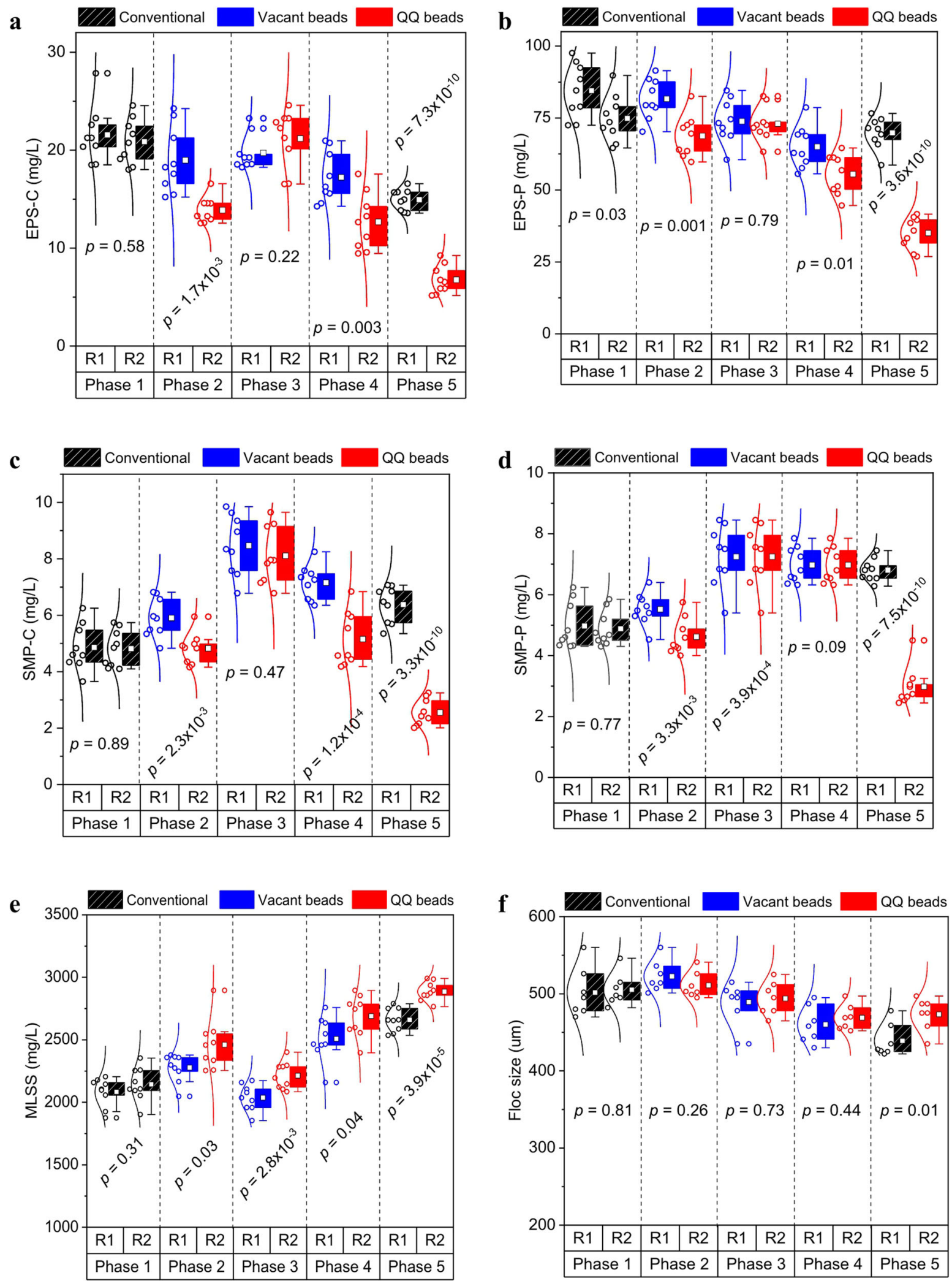

Fig. 2 Biopolymer concentrations and mixed liquor characteristics according to phases in the two MBRs. a EPS-carbohydrates (EPS-C); $\mathbf{b}$ EPS-proteins (EPS-P); c SMP-carbohydrates (SMP-C); d SMP-proteins (SMP-P); e mixed liquor suspended solids (MLSS); and $\mathbf{f}$ floc size. The box is determined by the 25 th and 75th percentiles, whereas the whiskers are determined by the 5th and 95th percentiles. The white square symbol inside each bar represents the average value of each parameter. 
a

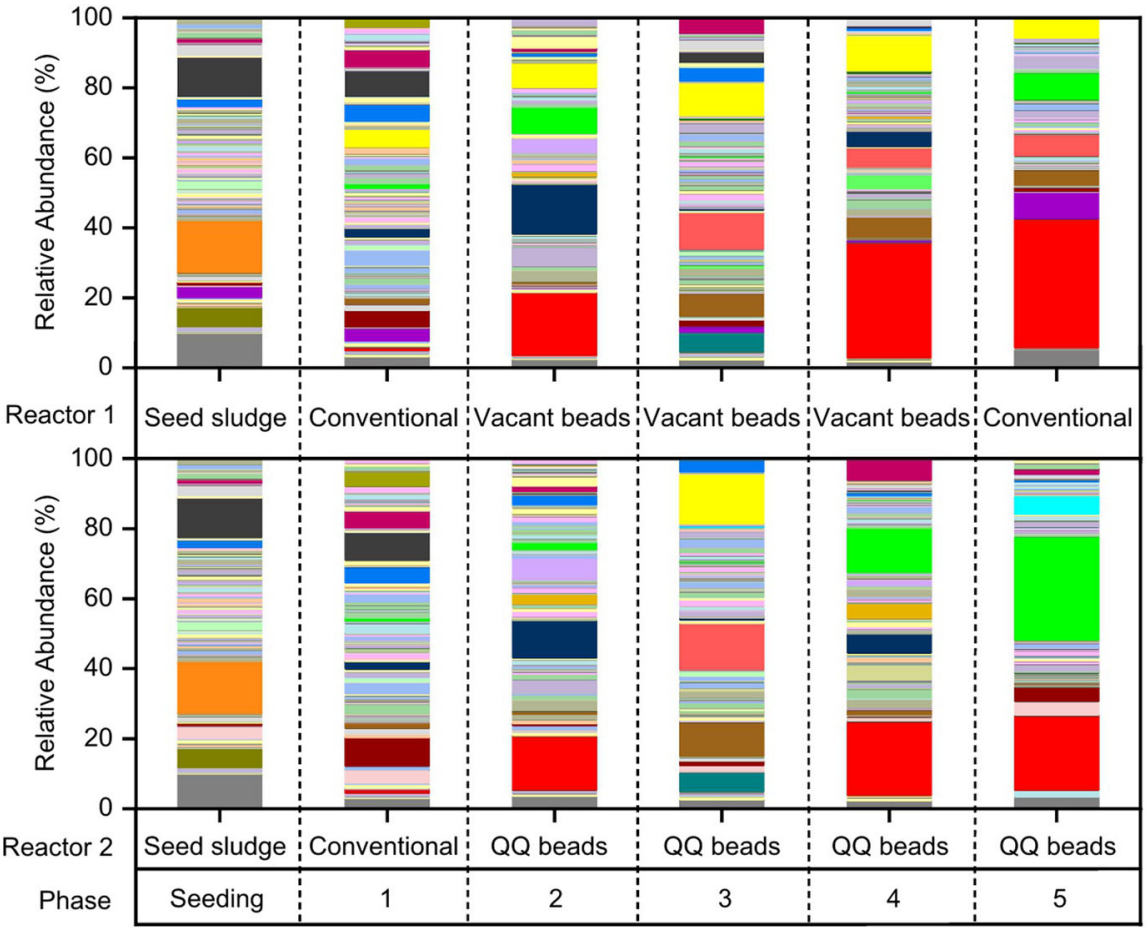

Chryseolinea serpens

Dokdonella immobilis

Ferruginibacter alkalilentus

Flavobacterium cheonhonense

Flavitalea antarctica

Koflera flava

Nannocystis konarekenis

Panacibacter ginsenosidivorans

Pedobacter glucosidilyticus

Runella slithyforms

Sphaerotilus natans

Sphingomonas piscinae

Tabrizicola aquatica

Terrimonas lutea

Thermomonas carbonis

Thiothrix eikelboomii

Tolumonas auensis

Others b

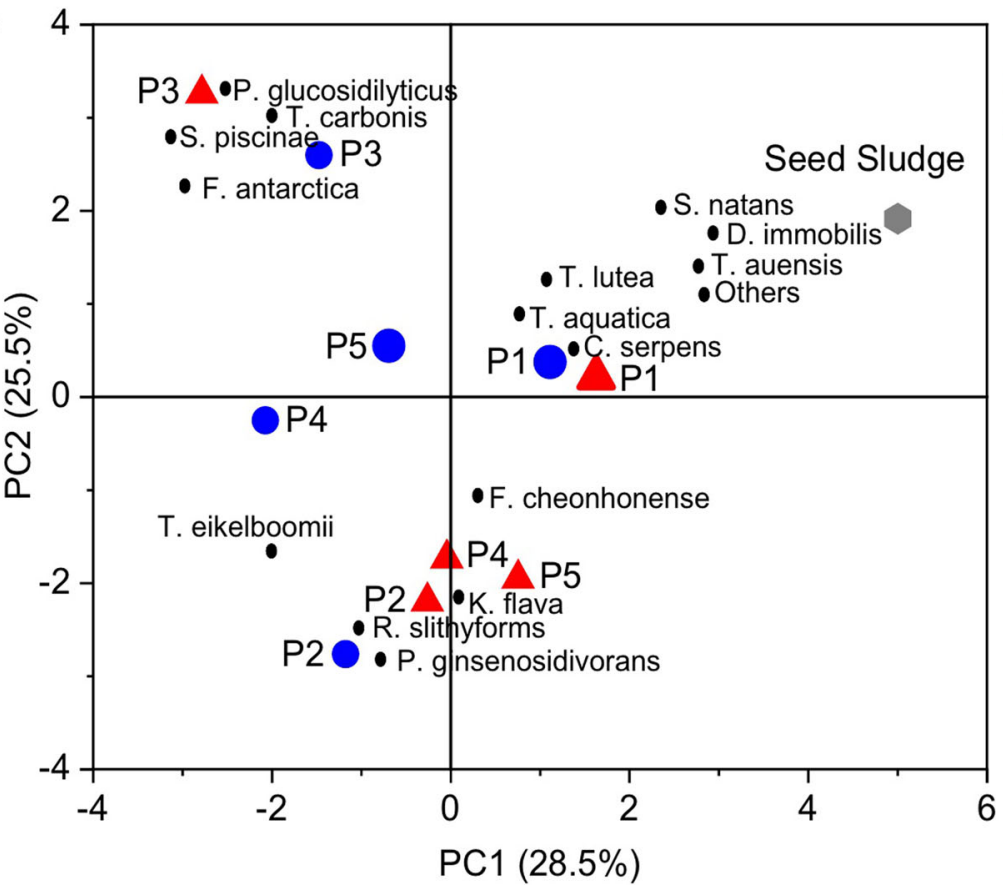

Seed Sludge

- R1

R2

Variations in the microbial community structures with phases in MBRs. a Species-level bacterial community composition. b Specieslevel principal component analysis (PCA) result using the dominant species given in Supplementary Table 2.

reduction in membrane fouling. In Phase 3 , the EPS-C concentration in Reactor 1 increased by $\sim 6 \%$, whereas it increased by $\sim 39.3 \%$ in Reactor 2 . This substantial EPS-C increase may have resulted in severe membrane fouling, even in the presence of $\mathrm{QQ}$ beads. A previous study reported that increased EPS production was strongly correlated with environmental stresses such as shear and starvation $^{37}$. It was thought that the disturbance at the beginning of Phase 3 may have caused a similar phenomenon. When the SRT was increased to $75 \mathrm{~d}$ in Phase 4, the EPS levels in the two MBRs decreased. In Reactor 1, EPS-C and EPS-P concentrations declined by $\sim 15.6 \%$ and $11 \%$, respectively, whereas their concentrations decreased by $\sim 74.4 \%$ and $21.65 \%$, respectively, in Reactor 2 . Similarly, previous studies also reported that EPS production was reduced with long SRT values ${ }^{11,38}$. In Phase 5, EPS-C and EPS-P contents continued to decrease in Reactor 2; however, no further decrease was observed in Reactor 1. The higher EPS content caused preferential attachment of biomass onto the membrane surface so as to form cake layers ${ }^{39}$. 
The reduced EPS production associated with the QQ strategy correlates with previous findings ${ }^{35,40}$. It is thus believed that membrane fouling could be mitigated by the presence of $\mathrm{QQ}$ media.

The SMP-carbohydrate (SMP-C) and SMP-protein (SMP-P) levels were also similar in both reactors in Phase $1(\sim 5$ and $4.5 \mathrm{mg} / \mathrm{L}$, respectively). In Phase 2 , there were slight changes in both. When disturbance was applied in Phase 3, the SMP levels in both reactors significantly increased. The SMP-C and SMP-P concentrations in Reactor 1 increased by $\sim 45.3 \%$ and $\sim 36.1 \%$, respectively, and their respective increases in Reactor 2 were more significant at $\sim 62.4 \%$ and $\sim 110 \%$. These results agree well with previous studies, which reported that the disturbance imposed on microorganisms induced the release of microbial polymeric substances $^{28,37}$, in addition to substrate limitations ${ }^{41}$. When the SRT was increased to $75 \mathrm{~d}$ in Phases 4 and 5, the SMP-C and SMP-P concentrations started decreasing, and the decline was more significant with QQ. For instance, in Phase 5, Reactor 2 had the lowest SMP-C and SMP-P levels, at $\sim 54.2 \%$ and $\sim 62.4 \%$ lower than these respective values in Phase 4 . In addition, the longer SRT contributed to decreased SMP levels when comparing Reactor 2 between Phases 2 and 5 . This result is consistent with previous studies $^{35,40}$, which reported that the presence of QQ media reduced soluble biopolymer contents in MBRs. Another previous study also reported that increasing the SRT in MBRs alleviated biofouling ${ }^{42}$. Notably, QQ caused the more substantive and immediate decrease of SMP-C than that of SMP-P in Phase 4. This could be associated with the inhibition of protease enzyme secretion in the presence of $\mathrm{QQ}$ enzymes leading to reduced degradation of soluble protein ${ }^{43}$. Overall, it can be concluded that the presence of $\mathrm{QQ}$ media reduced biopolymer production more significantly when the SRT was extended.

\section{Effects of QQ, disturbance, and SRT on mixed liquor characteristics and biological treatment efficiencies}

Mixed liquor characteristics, such as MLSS and floc size, were monitored over time (Fig. 2e, f). The MLSS concentration in both MBRs from Phases 1-3 varied in the range of $2100-2250 \mathrm{mg} / \mathrm{L}$. Disturbance (starvation with shear) at the beginning of Phase 3 caused a slight decrease in biomass concentration compared to that of Phase 2. At the longer SRT (75 d) in Phases 4 and 5, the MLSS concentration increased to $2650-2900 \mathrm{mg} / \mathrm{L}$. It is natural that a longer SRT should increase MLSS levels at the same yield. It appeared that the MLSS levels were a bit higher with QQ than without it as observed from Phase 2 through 5 . Microbial growth can be promoted if QS that requires carbon sources is inhibited. A recent finding pointed out that the $\mathrm{QQ}$ enzyme (acylase) may increase microbial yield, converting the resource (food) to more biomass $^{44}$. Operational parameters such as QQ, SRT, and disturbance did not yield significant changes in floc size during the entire study, although fluctuations were possible ${ }^{45}$. In this study, there was a slight increase in floc size with QQ in Phase 5. The microbial floc size is a function of several factors, such as QS, $\mathrm{QQ}$, nutrients, and operational conditions $\mathrm{s}^{43}$. A recent study reported that there was a negative correlation between floc size and EPS level, because the excessive EPS played a role in reducing the hydrophobicity of flocs and, thereby, weakening the cells' attachment ${ }^{46}$. It is thus seen that the reduced EPS content may help enhance the floc aggregation, possibly resulting in greater floc sizes.

The biological treatment efficiencies of the two MBRs were evaluated in terms of removals of chemical oxygen demand (COD), total organic carbon (TOC), total nitrogen (TN), and total phosphorus (TP) (Supplementary Fig. 3a-d). The effects of SRT and QQ on these removal efficiencies were almost negligible, although disturbance caused a slight decrease in organics removal. The result coincided with the increased SMP level with shear in Phase
3. In short, mixed liquor properties and biological treatment performances seemed to tolerate the effects of QQ and SRT, although they were slightly impacted by disturbance.

\section{Microbial community structure change}

Figure $3 a$ and Supplementary Table 2 show microbial community variations relative to phases, with clear microbial community structure shifts between phases. Two species were dominant in the seed sludge: Dokdonella immobilis (11.31\%) and Sphaerotilus natans (14.91\%). After inoculation in the laboratory MBRs, the dominance of these species diminished and other species, being adapted to the synthetic feed, flourished instead (Phase 1). In Phase 2, Thiothrix eikelboomii (15\%-18\%) and Panacibacter ginsenosidivorans $(11 \%-14 \%)$, which were negligible in the seed sludge, became dominant in both reactors. In addition, the relative abundances of Kofleria flava and Flavitalea antarctica increased to $7.57 \%$ and $6.95 \%$, respectively. These two species were more abundant in Reactor 1 than Reactor 2. Lastly, the major species of the seed sludge, such as D. immobilis, S. natans, and Terrimonas lutea, became minority species $(<0.5 \%)$ in Phase 2 . The effects of QQ on the species-level microbial community appeared to be minimal, although some of the major species (T. eikelboomii and $P$. ginsenosidivorans) were less abundant in Reactor 2 . This demonstrates that the adaptation of the sludge to the laboratory conditions led to dramatic changes in the microbial community composition; however, at short SRT, the community was not significantly impacted by $\mathrm{QQ}$.

A drastic change in the microbial community occurred with the disturbance applied at the beginning of Phase 3. Sphingomonas piscinae, Pedobacter glucosidilyticus, and F. antarctica, all of which belong to the previously reported biofilm-forming bacterial classes of Sphingobacteria ${ }^{47,48}$ and Alphaproteobacteria ${ }^{49}$, boomed after the disturbance. This result supported the occurrence of severe membrane fouling in Phase 3 as already shown above (see Fig. 1); however, there was a marginal difference in fouling between the reactors with vacant and $\mathrm{QQ}$ beads. It seemed that the disturbance counteracted the $\mathrm{QQ}$ effect.

When the biological treatment performances were stabilized from the disturbance of Phase 3, along with the longer SRT (see Supplementary Fig. 3), T. eikelboomii, $P$. ginsenosidivorans, and $K$. flava returned to the community in Phase 4 , but to different degrees, possibly owing to the $\mathrm{QQ}$ application. T. eikelboomii (32.93\%), F. antarctica $(10.25 \%)$, S. piscinae $(5.93 \%)$, P. glucosidilyticus $(5.58 \%)$, and $P$. ginsenosidivorans (4.43\%) were the dominant species without $\mathrm{QQ}$, whereas T. eikelboomii (21.08\%), K. flava (12.79\%), and $P$. ginsenosidivorans (5.47\%) were dominant with QQ. Two species, F. antarctica and $K$. flava, were distinct between the two reactors. The microbial communities of Phase 4 differed slightly from those of Phase 2, where $D$. immobilis and $K$. flava were major species in Reactor 1 . The result indicates that the microbial community recovers from the disturbance when relieved, but it is not the same as the previous state.

In Phase 5, it appears that the microbial communities in both reactors smoothly succeeded from those of Phase 4 . In Reactor 1 (conventional MBR), T. eikelboomii (36.75\%) became dominant, $T$. lutea $(7.49 \%)$ grew more, and $K$. flava $(7.70 \%)$ returned to the community in Reactor 1 . However, several species, such as $S$. piscinae $(0.5 \%), P$. glucosidilyticus $(0.00 \%)$, and $P$. ginsenosidivorans $(0.03 \%)$, virtually disappeared in Reactor 2 . With $Q Q$, the two species, T. eikelboomii and $K$. flava, dominated the microbial community, with $K$. flava occupying $\sim 30 \%$ of the whole community. Flavobacterium cheonhonense and Tabrizicola aquatica were detected in relatively large quantities in Reactor 2, although their abundances were smaller than those of $K$. flava. The result indicates that $K$. flava needs more time to grow; however, it may contribute to antifouling efficacy. The correlation between $K$. 
Table 1. Microbial diversity indices for the experimental samples in different phases.

\begin{tabular}{|c|c|c|c|c|c|c|c|}
\hline Phase & Reactor & Reads & OTUs & Chao1 & Shannon & Inverse Simpson & Good's coverage \\
\hline Seeding & Seed sludge & 24,717 & 651 & 547 & 4.42 & 0.96 & 0.997 \\
\hline 1 & $\mathrm{R} 1$ & 33,996 & 634 & 532 & 4.49 & 0.98 & 0.997 \\
\hline \multirow[t]{2}{*}{2} & $\mathrm{R} 1$ & 23,902 & 386 & 380 & 3.57 & 0.93 & 0.994 \\
\hline & R2 & 32,243 & 469 & 429 & 4.01 & 0.95 & 0.998 \\
\hline \multirow[t]{2}{*}{4} & $\mathrm{R} 1$ & 49,216 & 595 & 520 & 3.66 & 0.88 & 0.998 \\
\hline & R2 & 47,136 & 594 & 502 & 4.08 & 0.94 & 0.998 \\
\hline \multirow[t]{2}{*}{5} & $\mathrm{R} 1$ & 48,539 & 416 & 329 & 3.04 & 0.83 & 0.998 \\
\hline & R2 & 51,345 & 422 & 350 & 3.21 & 0.89 & 0.998 \\
\hline
\end{tabular}

flava and membrane fouling will be further discussed in later sections.

Microbial community structure can be further understood with their characteristics ${ }^{2,50}$. K. flava belongs to the order myxobacteria, Gram-negative, rod-shaped aerobic bacteria, which are a subgroup of the phylum Proteobacteria. These bacteria are excellent producers of secondary metabolites with antibacterial and antifungal properties ${ }^{51}$, and degrade complex biomolecules such as cellulose ${ }^{52}$. In contrast, $T$. eikelboomii has been reported as a filamentous microbe that secretes extracellular polymers and causes sludge bulking in $\mathrm{MBRs}^{53}$, resulting in biofilm formation and serious membrane fouling ${ }^{54,55}$. The longer SRT (75 d) may help the growth of these two species in the MBRs while preventing their washout with sludge wastage. QQ can exert a selection pressure on microbial community composition. Thus, the microbial community balance between $K$. flava and T. eikelboomii may have eventually dictated membrane-biofouling outcome. QQ with longer SRT helps endogenous bacteria (e.g., K. flava) antagonistic to biofilm-forming bacteria (e.g., T. eikelboomii) grow, further leading to reduced membrane fouling.

Principal component analysis (PCA) results show the changes in the microbial community structures between the operating phases (Fig. 3b). With the acclimation of seed sludge in the laboratory MBRs fed with synthetic wastewater, the microbial community structure moved to the center (Phase 1), corresponding to the left and downward from the seed sludge position. The community structure further moved downward in Phase 2. The effect of $\mathrm{QQ}$ on the microbial community appeared to be insignificant at short SRT. However, the disturbance introduced in Phase 3 significantly changed the microbial community structure, moving the direction upward and to the left along the vertical axis. With stabilization in the presence of QQ (Phases 4 and $5)$, the microbial community structure returned to the position seen before the disturbance. Without $\mathrm{QQ}$, however, the microbial community was clustered left of the center. The effect of QQ on PCA of microbial community structures was distinct from the one without $\mathrm{QQ}$ as the abundances of specific bacterial species changed with SRT, as discussed above. Thus, it is believed that QQ had an effect on the collective microbial community structure at long SRT and, consequently, the membrane-fouling propensity that can be induced by certain species of the microbial community was compromised ${ }^{56}$.

\section{Microbial diversity change}

The total effective readings of the 11 biomass samples were between 23,902 and 51,345, and the normalized number of reads was 23,902 . The coverage indices of all the samples were more than 0.994 , which indicates the detection of most bacterial species with high data reliabilities. Table 1 provides the operational taxonomic units (OTUs) and a-diversity (Chao1, Shannon, and Inverse Simpson) indices at the normalized sequencing depth. Microbial community richness values of Reactors 1 and 2 in Phase 2 were significantly lower (28.6-30.5\% and $21.6-26.7 \%)$ than those of the seed sludge and Phase 1 mixed liquors. After applying disturbance at the beginning of Phase 3 , these values increased by $55.8 \%$ and $31.0 \%$, respectively. The richness then decreased with stabilization in Phases 4 and 5. There were no significant differences between the reactors during each phase. These findings are similar to those from a previous study ${ }^{57}$. The reduced richness in Phases 2 and 4 can be ascribed to the feed type changing from real to synthetic wastewater and to relief from the imposed disturbance, respectively ${ }^{58}$. In contrast, the higher richness observed in Phase 3 can be attributed to disturbance. The Shannon and Inverse Simpson diversity indices showed similar trends to the Chao1 index, indicating the predominance of selective species with the adaptation of seed sludge in the laboratory MBRs, in addition to mixed liquor stabilization after disturbance. Interestingly, the microbial diversity was always greater with $\mathrm{QQ}$ than in the control. This indicates that $\mathrm{QQ}$ may disturb the existing microbial community, leading to a more diverse structure. In addition, diversity decreased with the longer SRT, possibly because of the survival and dominance of species more fit to environmental conditions with higher sludge ages.

\section{Correlation analysis for MBR fouling and biological characteristics}

Figure 4 summarizes the Spearman's correlation coefficients between MBR membrane fouling, mixed liquor characteristics, treatment efficiencies, and microbial communities using the entire experimental data obtained during this study. The fouling rate had strong, positive correlations $(r>0.7)$ with SMP-C, SMP-P, and the relative abundance of four individual microbial species (i.e., $F$. antarctica, P. glucosidilyticus, S. piscinae, and T. carbonis). SMP had a lot stronger correlations with fouling rates than EPS, although the actual amounts of the former were a lot smaller than those of the latter. The result indicates that the soluble biopolymers present in the bulk liquid play a more important role in membrane fouling, possibly due to their direct deposition onto the membrane surface. The strong, negative correlations of fouling rates with $C O D$ and TOC removal efficiencies support the above explanation. In particular, P. glucosidilyticus and S. piscinae, which had the highly strong correlations with membrane fouling $(r>$ 0.87), accordingly exhibited strong correlations with SMP. Notably, T. eikelboomii, which was the most abundant in Reactor 1 of Phases 4 and 5, had a relatively weak negative correlations ( $r=$ -0.32 ) with membrane fouling and so not as strong as did $K$. flava 


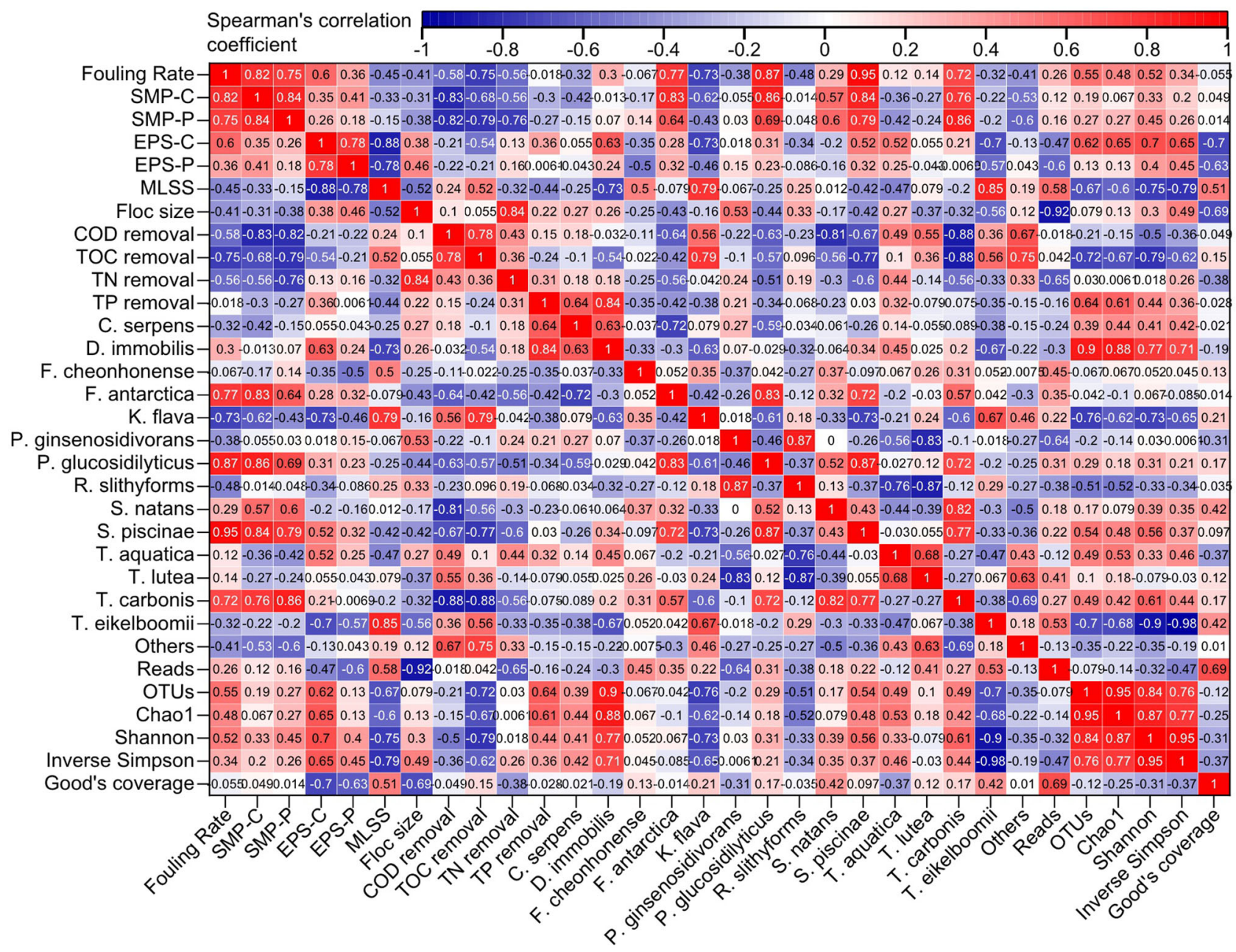

Fig. 4 Correlation analysis. Spearman's correlation coefficients between all the MBR parameters determined in the study.

$(r=-0.73)$. The decrease in the relative abundance of $T$. eikelboomii in Reactor 2 of Phase 5 should be associated with $\mathrm{QQ}$, but the species might still have been contributing to membrane fouling, as discussed above. As expected, the microbial diversity indices between OTUs and Chao1, as well as Shannon and inverse Simpson, were found to be strongly correlated. However, the fouling rate did not have strong correlations with any of the microbial diversity indices $(-0.05 \leq r \leq 0.55)$, although the microbial diversity was always higher in the presence of QQ (see Table 1).

On the other hand, the content of EPS-C and EPS-P had strong, negative correlations with MLSS levels. The biomass increase was accompanied with longer SRT, so the aged sludge produced less EPS amounts leading to the floc size decline (corresponding to a negative correlation, i.e., $r=-0.52$ ). Notably, the floc size had a strong, positive correlation ( $r=0.84$ ) with TN removal, suggesting that simultaneous nitrification and denitrification possibly occurred with larger biological flocs ${ }^{59}$. In addition, D. immobilis showed a strong positive correlation $(r=0.84)$ with TP removal, proposing its role as a potential phosphate uptake $\operatorname{strain}^{60}$. Overall, the relationships between MBR parameters (e.g., fouling rates, mixed liquor characteristics, biological treatment efficiencies, and microbial species dominance) helped better understand the fouling patterns and biological performances in the MBRs with and without QQ.

In summary, the QQ effect on MBR antifouling efficacy was clearer when the SRT was extended from 50 to $75 \mathrm{~d}$, although the disturbance (starvation with shear) aggravated membrane fouling, which counteracted the positive $\mathrm{QQ}$ effect. QQ yielded a significant biopolymer production decrease with the longer SRT. Accordingly, organic substance removal showed relatively strong, negative correlations with MBR-fouling propensity. MBR microbial communities showed dynamic responses to the feed change, $Q Q$, disturbance, and SRT. With disturbance, F. antarctica, S. piscinae, and $P$. glucosidilyticus dominated the microbial community leading to substantive membrane fouling. However, the microbial community balance between $T$. eikelboomii and $K$. flava, whose relative abundances appeared to be affected by SRT and QQ, played a key role in fouling propensity under stabilized conditions. The correlation analysis showed strong positive relationships between membrane fouling rate and the abundance of several microbial species (F. antarctica, P. glucosidilyticus, S. piscinae, and T. carbonis). However, there was no strong correlation between T. eikelboomii and membrane fouling propensity, possibly due to the antagonism by $K$. flava, and vice versa.

\section{METHODS}

\section{Feed wastewater}

We prepared synthetic wastewater (composition listed in Supplementary Table 3) every day in the laboratory ${ }^{40}$. Before being fed into the MBRs, the synthetic wastewater was put in a fridge $\left(4^{\circ} \mathrm{C}\right)$. The levels of COD, TOC, TN, and TP in the synthetic wastewater were $200 \pm 10,49.0 \pm 5.0,35 \pm 2.5$, and $7.0 \pm 1.5 \mathrm{mg} / \mathrm{L}$, respectively. 


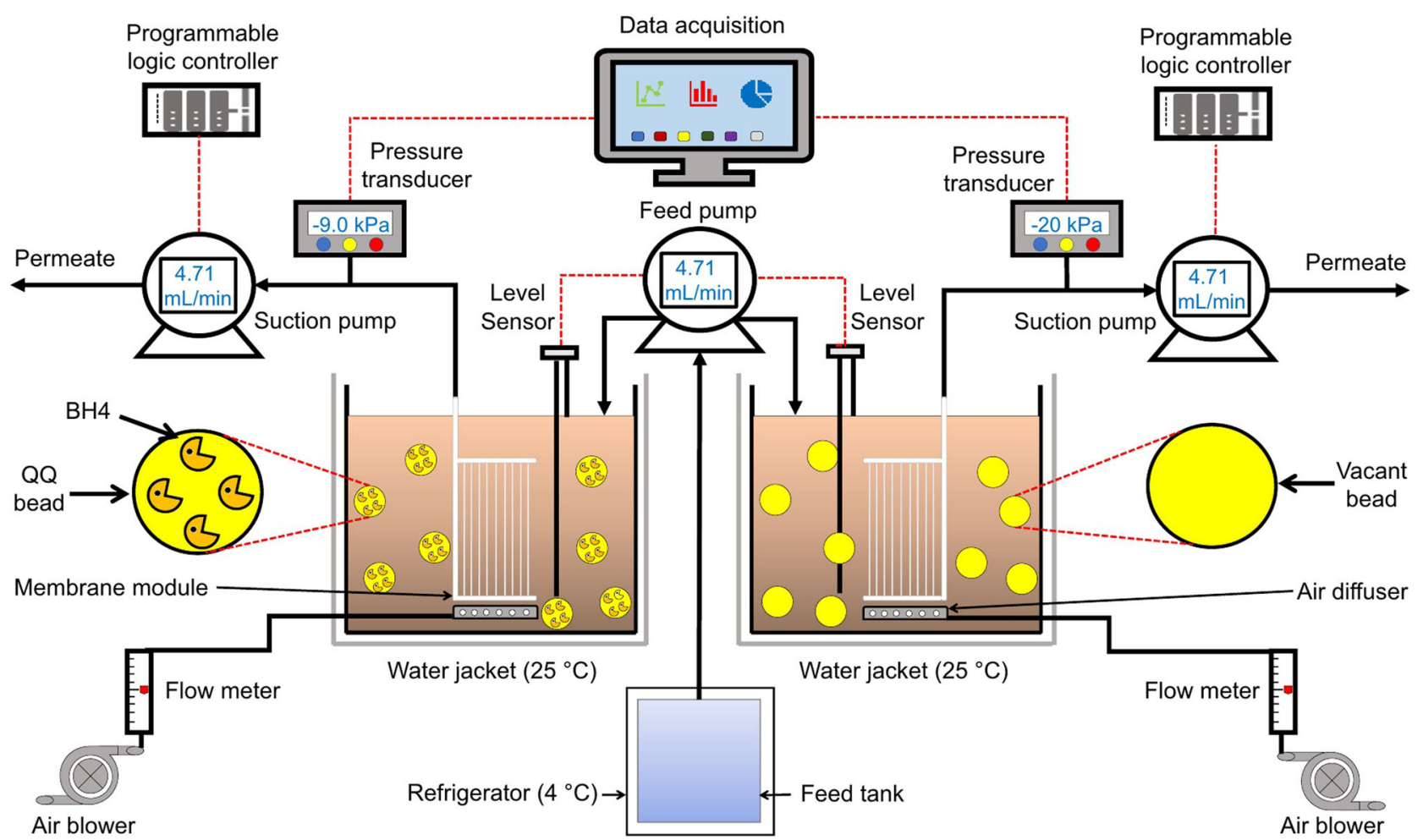

Fig. 5 Reactor configurations. Schematic of the laboratory-scale MBRs operated under different conditions, which are detailed in Table 2.

\begin{tabular}{|c|c|c|c|c|c|c|}
\hline 1 & $1-30$ & 50 & Conventional & Conventional & 0 & 0 \\
\hline 2 & $31-60$ & 50 & Vacant beads & QQ beads & 0 & 100 \\
\hline 5 & $136-165$ & 75 & Conventional & $\mathrm{QQ}$ beads & 0 & 100 \\
\hline
\end{tabular}

\section{Preparation of QQ beads}

We prepared QQ beads containing Rhodococcus sp. BH4 (8 mg dry mass per $\mathrm{mL}$ ) and two polymers, such as sodium alginate (Junsei Chemical Co, Ltd, Japan) and polyvinyl alcohol (Wako Chemicals, Japan), with slight modification $^{61}$. Briefly, we cultured colonies of QQ bacteria (Rhodococcus sp. BH4) on a Luria-Bertani (LB) agar plate and used a single colony to obtain the liquid seed culture in an LB broth $(50 \mathrm{~mL})^{62}$. The BH4 cells were further cultivated by adding $500 \mu \mathrm{L}$ of the seed culture to $100 \mathrm{~mL}$ of LB broth, after which the culture was separated using a centrifuge $(13,700 \times g$, $10 \mathrm{~min}, 4^{\circ} \mathrm{C}$ ). The BH4 cell pallets were collected and resuspended in $5 \mathrm{~mL}$ of deionized water. We then prepared a polymer solution containing polyvinyl alcohol and sodium alginate in deionized water with a respective mass ratio of $10: 1: 100$. To prepare QQ beads, the polymer solution $(20 \mathrm{~mL})$ and $\mathrm{BH} 4$ resuspension $(5 \mathrm{~mL})$ were mixed, and the resulting mixture was added dropwise into a cross-linking solution containing 1.13 $\mathrm{M}$ boric acid and $0.27 \mathrm{M} \mathrm{CaCl}_{2}$ using a syringe pump $(1 \mathrm{~mL} / \mathrm{min})$. The mixture was soaked in the solution for $4 \mathrm{~h}$ and then stabilized in $0.5 \mathrm{M}$ $\mathrm{Na}_{2} \mathrm{SO}_{4}$ solution for an additional $8 \mathrm{~h}$. Vacant beads (i.e., beads without $\mathrm{QQ}$ bacteria) were prepared following the same techniques described above, but using an equivalent volume of deionized water instead of the $\mathrm{BH} 4$ resuspension.

\section{MBR operations}

Two identical laboratory-scale submerged MBRs, each comprising a $2 \mathrm{~L}$ rectangular reactor, Kolon polyvinyl difluoride (PVDF) hollow fiber membrane, and an air diffuser were designed, built, and operated under prearranged conditions (Fig. 5 and Table 2). The reactor volume was kept constant at $2 \mathrm{~L}$ using a conductivity level sensor and the reactor temperature (mixed liquor) was kept at $25^{\circ} \mathrm{C}$ by circulating water from a temperature-controlled water bath through the jacket that surrounded the reactor. The PVDF membrane had a pore size of $0.1 \mu \mathrm{m}$, but the effective surface area $\left(94.2\right.$ or $\left.113.4 \mathrm{~cm}^{2}\right)$ changed according to the membrane flux $\left(25\right.$ or $30 \mathrm{~L} / \mathrm{m}^{2} \mathrm{~h}$ ). The aeration rate was set to $1.0 \mathrm{~L} / \mathrm{min}$, equivalent to $72 \mathrm{~s}^{-1}$ as a velocity gradient value ${ }^{31}$. Membrane operation was cyclical, with 19 min suction under a vacuum followed by 1 min relaxation (i.e., no permeate flow). The operation cycle was executed based precisely on the given inputs in an LG K7M-DR30S programmable logic controller (Korea). Each reactor's TMP was continuously collected in a data acquisition system consisting of an SMC ZSE40F pressure sensor (Japan), a Metex M-3850D digital multitester (Korea), and a notebook computer ${ }^{63}$.

The MBR operation schemes were divided into five phases, which are detailed in Table 2. In Phase 1, the two reactors were inoculated using seed sludge collected from the Shincheon Municipal Wastewater Treatment Plant, Daegu, Korea, after which the reactors were operated in 
conventional mode (i.e., with no media). In Phases 2-4, Reactor 1 was operated with vacant beads added (control MBR) and Reactor 2 was operated with QQ beads added (QQ MBR). In Phase 5, Reactor 1 was switched back to conventional mode, but Reactor 2 was maintained as a QQ MBR. The media content of both vacant and QQ beads in the MBRs was $1.25 \%(\mathrm{v} / \mathrm{v})$ and the corresponding BH4 concentration in the QQ MBR was $100 \mathrm{mg} / \mathrm{L}$ of reactor volume. The MBRs were all operated at a constant flux of $30 \mathrm{~L} / \mathrm{m}^{2} \mathrm{~h}$ in Phases 1 and 2 , and at $25 \mathrm{~L} / \mathrm{m}^{2} \mathrm{~h}$ in Phases $3-5$. The hydraulic retention time was set to $7.43 \mathrm{~h}$, but the SRT was adjusted to $50 \mathrm{~d}$ for Phases 1-3 and to $75 \mathrm{~d}$ for Phases 4 and 5. MBR operations during the experimental runs were stopped when the TMP reached $\sim 50 \mathrm{kPa}$, after which the fouled membrane was replaced. The average membrane fouling rate $(\mathrm{kPa} / \mathrm{d})$, which was defined as the increase in TMP from 4-6 kPa (initial TMP value) to $\sim 50 \mathrm{kPa}$ per elapsed time, was estimated. Notably, we never mixed the MBR-activated sludge between the two reactors during the entire experimental period $(165 \mathrm{~d})$ after seeding. Biomass samples for microbial community analysis were collected at the end of each phase.

At the beginning of Phase 3 (during the first $2 \mathrm{~d}$ ), disturbance (i.e. starvation with high shear) was imposed on both reactors to disturb their respective microbial communities. A high shear rate (corresponding to a velocity gradient of $103 \mathrm{~s}^{-1}$ ) was imparted on the MBR mixed liquor by reducing the mixed liquor volume to $1 \mathrm{~L}$ at an air flow rate of $1 \mathrm{~L} / \mathrm{min}$. No feed was supplied during this period.

\section{Analytical methods}

SMP and EPS amounts were determined following methods described below $^{35,45}$. A $50 \mathrm{~mL}$ mixed liquor sample taken from the MBR was centrifuged at 4000 r.p.m. $(2951 \times g)$ for $20 \mathrm{~min}$ and the resulting supernatant was passed through a $0.45 \mu \mathrm{m}$ filter (Millipore, USA). The filtrate was then utilized to analyze SMP components (i.e., carbohydrates and proteins) and the sediment (pellet) was suspended again in a $0.9 \% \mathrm{NaCl}$ solution $(50 \mathrm{~mL})$. The suspension was placed in an $80^{\circ} \mathrm{C}$ oven for $30 \mathrm{~min}$ for EPS extraction and then removed from it to cool down to room temperature. The sample proceeded through a centrifuge ( 4000 r.p.m., $20 \mathrm{~min}$ ) and the supernatant was filtered through a $0.45 \mu \mathrm{m}$ membrane filter to collect the EPS fraction. The concentrations of SMP and EPS-proteins (i.e., SMP-P and EPS-P) were determined according to a modified Lowry method ${ }^{64}$, whereas the concentrations of SMP and EPS-carbohydrates (i.e., SMP-C and EPS-C) were determined by the phenol-sulfuric acid method ${ }^{65}$. The dichromate method $^{66}$ was adopted to determine COD using a Metrohm 809 Titrando automatic titrator (Switzerland) ${ }^{35}$. TOC, TN, and TP were measured using a TOC analyzer (Sievers 800 TOC Analyzer, USA), Hach Persulfate Digestion Test 'N Tube method, and Humas HS-TP-H Molybdo Vanadate method, respectively ${ }^{35}$. The levels of MLSS were determined based on dried weight at $103^{\circ} \mathrm{C}^{66}$ and the microbial floc size was measured using a Beckman Coulter LS 13320 laser diffraction particle size analyzer (USA $)^{45}$.

\section{Gene sequencing and assays}

The microbial community analysis of the seed sludge and MBR mixed liquor samples was conducted ${ }^{67}$. Briefly, DNA was extracted using a DNeasyPowerSoil Kit (Qiagen, Hilden, Germany) and then the extracted DNA was quantified using Quant-IT PicoGreen (Invitrogen). The sequencing library preparation was performed following the Illumina $16 \mathrm{~S}$ Metagenomic Sequencing Library protocols to amplify the V3-V4 region (341F-805R). The universal polymerase chain reaction primer pair used for the amplifications was: V3-F: $5^{\prime}$-TCGTCGGCAGCGTCAGATGTGTATAAGAG ACAGCCTACGGGNGGCWGCAG-3', V4-R: 5'-GTCTCGTGGGCTCGGAGATGTGTATAAGAGACAGGACTACHVGGGTATCTAATCC- $3^{\prime}$. The MiSeq $^{\text {TM }}$ platform (Illumina, San Diego, USA) was employed to carry out the paired-end $(2 \times 300 \mathrm{bp})$ gene sequencing by the Macrogen (Korea). All sequence reads were compared to data from the Silva rRNA database using the basic local alignment search tool and taxonomic assignments of the sequence reads were performed using the National Center for Biotechnology Information Taxonomy Database (USA). The reads were normalized with the single_rarefaction.py script from the QIIME software with parameter -d 23902 (the lowest depth number of sequences to subsample per sample) ${ }^{68}$ and a-diversity indices (Chao1, Shannon, and Inverse Simpson) were calculated with the normalized sequencing depth to avoid any bias using the diversity function in the R package "vegan" microbial community structures using Origin 2019 software. The Chao1, Shannon, and Inverse Simpson values, which respectively represent the richness, diversity, and evenness of the microbial community, were estimated using microbial community data.

\section{DATA AVAILABILITY}

The raw sequence data of dominant species that support our findings of this study have been deposited in the Sequence Read Archive with the Accession Number PRJNA699403.

Received: 15 October 2020; Accepted: 17 February 2021; Published online: 19 March 2021

\section{REFERENCES}

1. Fountoulakis, M. S., Markakis, N., Petousi, I. \& Manios, T. Single house on-site grey water treatment using a submerged membrane bioreactor for toilet flushing. Sci. Total Environ. 551-552, 706-711 (2016).

2. Gurung, K., Ncibi, M. C. \& Sillanpää, M. Assessing membrane fouling and the performance of pilot-scale membrane bioreactor (MBR) to treat real municipal wastewater during winter season in nordic regions. Sci. Total Environ. 579, 1289-1297 (2017).

3. Pervez, M. N. et al. A critical review on nanomaterials membrane bioreactor (NMsMBR) for wastewater treatment. npj Clean Water 3, 43 (2020).

4. Silva, A. F. et al. Impact of sludge retention time on the fine composition of the microbial community and extracellular polymeric substances in a membrane bioreactor. Appl. Microbiol. Biotechnol. 100, 8507-8521 (2016).

5. Gurung, K., Ncibi, M. C. \& Sillanpää, M. Removal and fate of emerging organic micropollutants (EOMs) in municipal wastewater by a pilot-scale membrane bioreactor (MBR) treatment under varying solid retention times. Sci. Total Environ. 667, 671-680 (2019).

6. Judd, S. The MBR Book: Principles and Applications of Membrane Bioreactors for Water and Wastewater Treatment (Elsevier, 2010).

7. Drews, A. Membrane fouling in membrane bioreactors-characterisation, contradictions, cause and cures. J. Membr. Sci. 363, 1-28 (2010).

8. Liang, S., Liu, C. \& Song, L. Soluble microbial products in membrane bioreactor operation: behaviors, characteristics, and fouling potential. Water Res. 41, 95-101 (2007).

9. Trussell, R. S., Merlo, R. P., Hermanowicz, S. W. \& Jenkins, D. The effect of organic loading on process performance and membrane fouling in a submerged membrane bioreactor treating municipal wastewater. Water Res. 40, 2675-2683 (2006).

10. Han, S.-S., Bae, T.-H., Jang, G.-G. \& Tak, T.-M. Influence of sludge retention time on membrane fouling and bioactivities in membrane bioreactor system. Process. Biochem. 40, 2393-2400 (2005).

11. Ahmed, Z., Cho, J., Lim, B.-R., Song, K.-G. \& Ahn, K.-H. Effects of sludge retention time on membrane fouling and microbial community structure in a membrane bioreactor. J. Membr. Sci. 287, 211-218 (2007).

12. Hu, M., Wang, X., Wen, X. \& Xia, Y. Microbial community structures in different wastewater treatment plants as revealed by 454 -pyrosequencing analysis. Bioresour. Technol. 117, 72-79 (2012).

13. $\mathrm{Wu}, \mathrm{B} ., \mathrm{Yi}, \mathrm{S}$. \& Fane, A. G. Microbial behaviors involved in cake fouling in membrane bioreactors under different solids retention times. Bioresour. Technol. 102, 2511-2516 (2011).

14. Parsek, M. R. \& Greenberg, E. P. Sociomicrobiology: the connections between quorum sensing and biofilms. Trends Microbiol. 13, 27-33 (2005).

15. Whitehead, N. A., Welch, M. \& Salmond, G. P. C. Silencing the majority. Nat. Biotechnol. 19, 735 (2001).

16. Lee, K., Yu, H., Zhang, X. \& Choo, K.-H. Quorum sensing and quenching in membrane bioreactors: opportunities and challenges for biofouling control. Bioresour. Technol. 270, 656-668 (2018).

17. Yeon, K.-M. et al. Quorum sensing: a new biofouling control paradigm in a membrane bioreactor for advanced wastewater treatment. Environ. Sci. Technol. 43, 380-385 (2009).

18. Oh, H.-S., Kim, S.-R., Cheong, W.-S., Lee, C.-H. \& Lee, J.-K. Biofouling inhibition in MBR by Rhodococcus sp. Bh4 isolated from real mbr plant. Appl. Microbiol. Biotechnol. 97, 10223-10231 (2013).

19. Gül, B. Y., Imer, D. Y., Park, P.-K. \& Koyuncu, I. Selection of quorum quenching (QQ) bacteria for membrane biofouling control: effect of different Gram-staining QQ bacteria, Bacillus sp. T5 and Delftia sp. T6, on microbial population in membrane bioreactors. Water Sci. Technol. 78, 358-366 (2018).

20. Ergön-Can, T., Köse-Mutlu, B., Koyuncu, İ. \& Lee, C.-H. The use of the new quorum quenching isolate of Bordetella hinzii s3 to prevent biofouling in membrane bioreactor systems. Waste Biomass-. Valor 11, 3513-3523 (2020).

21. Ham, S.-Y., Kim, H.-S., Cha, E., Park, J.-H. \& Park, H.-D. Mitigation of membrane biofouling by a quorum quenching bacterium for membrane bioreactors. Bioresour. Technol. 258, 220-226 (2018). 
22. Gu, Y. et al. Quorum quenching activity of indigenous quorum quenching bacteria and its potential application in mitigation of membrane biofouling. J. Chem. Technol. Biotechnol. 93, 1394-1400 (2018).

23. Lee, K. et al. Stopping autoinducer- 2 chatter by means of an indigenous bacterium (Acinetobacter sp. Dky-1): a new antibiofouling strategy in a membrane bioreactor for wastewater treatment. Environ. Sci. Technol. 52, 6237-6245 (2018).

24. Köse-Mutlu, B., Ergön-Can, T., Koyuncu, I. \& Lee, C.-H. Quorum quenching for effective control of biofouling in membrane bioreactor: a comprehensive review of approaches, applications, and challenges. Environ. Eng. Res. 24, 543-558 (2019).

25. Shah, S. S. A. \& Choo, K.-H. Isolation and characterization of novel indigenous facultative quorum quenching bacterial strains for ambidextrous biofouling control. Bioresour. Technol. 308, 123269 (2020).

26. Tan, C. H. et al. The role of quorum sensing signalling in eps production and the assembly of a sludge community into aerobic granules. ISME J. 8, 1186 (2014).

27. $\mathrm{Yu}, \mathrm{H}$. et al. Biofouling control by biostimulation of quorum-quenching bacteria in a membrane bioreactor for wastewater treatment. Biotechnol. Bioeng. 113, 2624-2632 (2016).

28. Le-Clech, P., Chen, V. \& Fane, T. A. G. Fouling in membrane bioreactors used in wastewater treatment. J. Membr. Sci. 284, 17-53 (2006).

29. Xu, Z., Song, X., Li, Y., Li, G. \& Luo, W. Removal of antibiotics by sequencing-batch membrane bioreactor for swine wastewater treatment. Sci. Total Environ. 684, 23-30 (2019)

30. Wang, $H$. et al. Membrane fouling mitigation in different biofilm membrane bioreactors with pre-anoxic tanks for treating mariculture wastewater. Sci. Total Environ. 724, 138311 (2020).

31. Mueller, J., Boyle, W. C. \& Popel, H. J. Aeration: Principles and Practice Vol. 11 (CRC Press, 2002).

32. Meng, F., Shi, B., Yang, F. \& Zhang, H. New insights into membrane fouling in submerged membrane bioreactor based on rheology and hydrodynamics concepts. J. Membr. Sci. 302, 87-94 (2007).

33. Wu, S. C. \& Lee, C. M. Correlation between fouling propensity of soluble extracellular polymeric substances and sludge metabolic activity altered by different starvation conditions. Bioresour. Technol. 102, 5375-5380 (2011).

34. Jin, Y.-L. et al. Effect of do concentration on biofilm structure and membrane filterability in submerged membrane bioreactor. Water Res. 40, 2829-2836 (2006).

35. Iqbal, T., Lee, K., Lee, C.-H. \& Choo, K.-H. Effective quorum quenching bacteria dose for anti-fouling strategy in membrane bioreactors utilizing fixed-sheet media. J. Membr. Sci. 562, 18-25 (2018).

36. Lee, K. et al. Membrane biofouling behaviors at cold temperatures in pilot-scale hollow fiber membrane bioreactors with quorum quenching. Biofouling 34, 912-924 (2018).

37. Wang, Z., Wu, Z. \& Tang, S. Extracellular polymeric substances (EPS) properties and their effects on membrane fouling in a submerged membrane bioreactor. Water Res. 43, 2504-2512 (2009).

38. Jinsong, Z., Chuan, C. H., Jiti, Z. \& Fane, A. Effect of sludge retention time on membrane bio-fouling intensity in a submerged membrane bioreactor. Sep. Sci. Technol. 41, 1313-1329 (2006).

39. Charfi, A., Ben Amar, N. \& Harmand, J. Analysis of fouling mechanisms in anaerobic membrane bioreactors. Water Res. 46, 2637-2650 (2012).

40. Weerasekara, N. A., Choo, K.-H. \& Lee, C.-H. Biofouling control: bacterial quorum quenching versus chlorination in membrane bioreactors. Water Res. 103, 293-301 (2016).

41. Nagaoka, H., Kono, S. \& Hamaya, S. in IWA 2nd World Water Congress B1132 (IWA, Berlin, 2001).

42. Yu, H., Xu, G., Qu, F., Li, G. \& Liang, H. Effect of solid retention time on membrane fouling in membrane bioreactor: from the perspective of quorum sensing and quorum quenching. Appl. Microbiol. Biotechnol. 100, 7887-7897 (2016).

43. Salehiziri, M. et al. Investigating the influences of quorum quenching and nutrient conditions on activated sludge flocs at a short-time scale. Chemosphere 248, 125917 (2020)

44. McBride, S. G. \& Strickland, M. S. Quorum sensing modulates microbial efficiency by regulating bacterial investment in nutrient acquisition enzymes. Soil Biol. Biochem. 136, 107514 (2019)

45. Weerasekara, N. A., Choo, K.-H. \& Lee, C.-H. Hybridization of physical cleaning and quorum quenching to minimize membrane biofouling and energy consumption in a membrane bioreactor. Water Res. 67, 1-10 (2014).

46. Waheed, H., Xiao, Y., Hashmi, I. \& Zhou, Y. The selective pressure of quorum quenching on microbial communities in membrane bioreactors. Chemosphere 247, 125953 (2020)

47. Jinhua, P., Fukushi, K. \& Yamamoto, K. Bacterial community structure on membrane surface and characteristics of strains isolated from membrane surface in submerged membrane bioreactor. Sep. Sci. Technol. 41, 1527-1549 (2006).

48. Ma, J., Wang, Z., Yang, Y., Mei, X. \& Wu, Z. Correlating microbial community structure and composition with aeration intensity in submerged membrane bioreactors by 454 high-throughput pyrosequencing. Water Res. 47, 859-869 (2013).
49. $\mathrm{Ma}$, Z. et al. Effect of temperature variation on membrane fouling and microbial community structure in membrane bioreactor. Bioresour. Technol. 133, 462-468 (2013).

50. Zheng, W., Wen, X., Zhang, B. \& Qiu, Y. Selective effect and elimination of antibiotics in membrane bioreactor of urban wastewater treatment plant. Sci. Total Environ. 646, 1293-1303 (2019).

51. Weissman, K. J. \& Müller, R. A brief tour of myxobacterial secondary metabolism. Bioorg. Med. Chem. 17, 2121-2136 (2009).

52. Reichenbach, H. The ecology of the myxobacteria. Environ. Microbiol. 1, 15-21 (1999).

53. Wu, X. et al. Thiothrix eikelboomii interferes oxygen transfer in activated sludge. Water Res. 151, 134-143 (2019).

54. Wang, Z. et al. Optimisation and performance of naclo-assisted maintenance cleaning for fouling control in membrane bioreactors. Water Res. 53, 1-11 (2014).

55. Gao, D.-W., Wang, X.-L. \& Xing, M. Dynamic variation of microbial metabolites and community involved in membrane fouling in A/O-MBR. J. Membr. Sci. 458, 157-163 (2014).

56. Weerasekara, N. A. et al. Clues to membrane fouling hidden within the microbial communities of membrane bioreactors. Environ. Sci. Water Res. Technol. 5, 1389-1399 (2019).

57. Jo, S. J. et al. Effects of quorum quenching on the microbial community of biofilm in an anoxic/oxic mbr for wastewater treatment. J. Microbiol. Biotechnol. 26, 1593-1604 (2016)

58. Zheng, W. \& Wen, X. How exogenous influent communities and environmental conditions affect activated sludge communities in the membrane bioreactor of a wastewater treatment plant. Sci. Total Environ. 692, 622-630 (2019).

59. Choo, K.-H. \& Stensel, H. D. Sequencing batch membrane reactor treatment: nitrogen removal and membrane fouling evaluation. Water Environ. Res. 72, 490-498 (2000).

60. Liu, Y., Jin, J.-H., Liu, H.-C. \& Liu, Z.-P. Dokdonella immobilis sp. Nov., isolated from a batch reactor for the treatment of triphenylmethane dye effluent. Int. J. Syst. Evol. Microbiol. 63, 1557-1561 (2013).

61. Kim, S.-R. et al. Biofouling control with bead-entrapped quorum quenching bacteria in membrane bioreactors: physical and biological effects. Environ. Sci. Technol. 47, 836-842 (2013).

62. Iqbal, T., Salman Ali Shah, S., Lee, K. \& Choo, K.-H. Porous shell quorum quenching balls for enhanced anti-biofouling efficacy and media durability in membrane bioreactors. Chem. Eng. J. 406,126869 (2020).

63. Iqbal, T., Weerasekara, N. A., Lee, K. \& Choo, K.-H. Impact of encapsulated quorumquenching bacterial dose and feed type on biofouling control in membrane bioreactors. J. Environ. Eng. 146, 04019109 (2020).

64. Peterson, G. L. A simplification of the protein assay method of lowry et al. Which is more generally applicable. Anal. Biochem. 83, 346-356 (1977).

65. DuBois, M., Gilles, K. A., Hamilton, J. K., Rebers, P. A. \& Smith, F. Colorimetric method for determination of sugars and related substances. Anal. Chem. 28, 350-356 (1956).

66. APHA, E. Standard methods for the examination of water and wastewater. (American Public Health Association, American Water Works Association, and Water Environment Federation, 2012).

67. Scorza, C., Piccini, C., Busi, M. M., Carriquiry, J. A. A. \& Zunino, P. Alterations in the gut microbiota of rats chronically exposed to volatilized cocaine and its active adulterants caffeine and phenacetin. Neurotox. Res. 35, 111-121 (2019).

68. Caporaso, J. G. et al. Qiime allows analysis of high-throughput community sequencing data. Nat. Methods 7, 335-336 (2010).

69. Dixon, P. Vegan, a package of $r$ functions for community ecology. J. Veg. Sci. 14, 927-930 (2003).

\section{ACKNOWLEDGEMENTS}

This research was supported by a grant (number 2020K1A4A7A02108858) from the National Research Foundation of Korea, funded by the Korean government (Ministry of Science and ICT)

\section{AUTHOR CONTRIBUTIONS}

S.S.A.S. conducted the experiments, analyzed the data, and wrote the original draft. L. D.S. and G.B. conducted the experiments. H.P. and K.L. supported experimental methodology. M.F. and I.A. revised the manuscript. K.H.C. supervised the research and revised the manuscript.

\section{COMPETING INTERESTS}

The authors declare no competing interests. 


\section{ADDITIONAL INFORMATION}

Supplementary information The online version contains supplementary material available at https://doi.org/10.1038/s41545-021-00110-9.

Correspondence and requests for materials should be addressed to K.-H.C.

Reprints and permission information is available at http://www.nature.com/ reprints

Publisher's note Springer Nature remains neutral with regard to jurisdictional claims in published maps and institutional affiliations.
Open Access This article is licensed under a Creative Commons Attribution 4.0 International License, which permits use, sharing, adaptation, distribution and reproduction in any medium or format, as long as you give appropriate credit to the original author(s) and the source, provide a link to the Creative Commons license, and indicate if changes were made. The images or other third party material in this article are included in the article's Creative Commons license, unless indicated otherwise in a credit line to the material. If material is not included in the article's Creative Commons license and your intended use is not permitted by statutory regulation or exceeds the permitted use, you will need to obtain permission directly from the copyright holder. To view a copy of this license, visit http://creativecommons.org/licenses/by/4.0/.

(c) The Author(s) 2021 